\title{
Short communication: Measures of weight distribution and frequency of steps as indicators of restless behavior
}

\author{
N. Chapinal, ${ }^{\star 1}$ A. M. de Passillé, $†$ J. Rushen, $†$ and C. B. Tuckerł \\ *Animal Welfare Program, University of British Columbia, 2357 Main Mall, Vancouver, BC, V6T 1Z4, Canada \\ †Agriculture and Agri-Food Canada, PO Box 1000, Agassiz, BC, V0M 1A0, Canada \\ ‡Department of Animal Science, University of California, 1 Shields Ave., Davis 95616
}

\begin{abstract}
Restless behavior, as measured by the steps taken or weight shifting between legs, may be a useful tool to assess the comfort of dairy cattle. These behaviors increase when cows stand on uncomfortable surfaces or are lame. The objective of this study was to compare 2 measures of restless behavior, stepping behavior and changes in weight distribution, on 2 standing surfaces: concrete and rubber. Twelve cows stood on a weighing platform with 1 scale/hoof for $1 \mathrm{~h}$. The platform was covered with either concrete or rubber, presented in a crossover design. Restlessness, as measured by both the frequency of steps and weight shifting (measured as the standard deviation of weight applied over time to the legs), increased over $1 \mathrm{~h}$ of forced standing on either concrete or rubber. A positive relationship was found between the frequency of steps and the standard deviation of weight over $1 \mathrm{~h}$ for both treatments and pairs of legs $(r \geq 0.66)$. No differences existed in the standard deviation of weight applied to the front (27.6 $\pm 1.6 \mathrm{~kg})$ or rear legs $(33.5 \pm 1.4 \mathrm{~kg})$ or the frequency of steps $(10.2 \pm 1.6$ and $20.8 \pm 3.2$ steps/10 min for the front and rear pair, respectively) between rubber and concrete. Measures of restlessness are promising tools for assessing specific types of discomfort, such as those associated with lameness, but additional tools are needed to assess comfort of non-concrete standing surfaces.
\end{abstract}

Key words: comfort, flooring, restless behavior, lameness

\section{Short Communication}

Restlessness, as measured by stepping rate or weight shifting between legs, may be a useful tool to assess the comfort of dairy cattle. For example, when forced to stand on concrete after morning milking, cows step more frequently the longer they stand (Cooper et al.,

Received June 11, 2010.

Accepted October 14, 2010.

${ }^{1}$ Corresponding author: nchapinal@yahoo.com
2007, 2008; Krebs et al., 2011). Lame cattle shift their weight more than sound cows while standing (Chapinal et al., 2010a,b), and this behavior is decreased when lame cows are given pain relief (Rushen et al., 2007).

Despite the growing evidence that concrete flooring is uncomfortable, little work has evaluated the important characteristics of alternative surfaces, particularly for standing behavior. Recent research has shown that flooring that is softer can improve cow mobility (Telezhenko and Bergsten, 2005; Rushen and de Passillé, 2006; Flower et al., 2007) and cattle show distinct preferences for softer flooring for standing on (Lowe et al., 2001; Tucker et al., 2006). Alternative flooring materials that have more friction and are more compressible than concrete should be considered for dairy barns, but we lack simple means of assessing the comfort of different flooring materials.

The objectives of the current study were: a) to compare measures of restlessness, namely frequency of steps and changes in weight distribution measured with a weighing platform, and b) to assess changes in weight distribution and stepping behavior associated with different standing surfaces and standing time.

Twelve lactating Holstein cows (mean $\pm \mathrm{SD}$; parity $=2.5 \pm 0.7 ; \mathrm{BW}=712 \pm 51 \mathrm{~kg} ; \mathrm{DIM}=233 \pm 72 \mathrm{~d}$; daily milk production $=36.2 \pm 5.5 \mathrm{~kg}$ ) were selected for the current study. Cows were housed in sand-bedded freestalls $(2.4-\mathrm{m}$ long $\times 1.2-\mathrm{m}$ wide $\times 0.4-\mathrm{m}$ deep $)$ at the University of British Columbia's Dairy Education and Research Centre in Agassiz, Canada. Cows were housed in groups of 12 to 36 cows and provided with at least 1 freestall per animal. Cows were fed a TMR diet twice daily, formulated to meet requirements for dairy cows (NRC, 2001). Water was freely available. Cows were milked in the parlor at approximately 0800 and $1700 \mathrm{~h}$ daily. The experimental protocol was approved by the University of British Columbia Institutional Animal Care Committee, which is monitored by the Canadian Council on Animal Care.

We measured how cows changed their weight distribution and frequency of steps when standing on a weighing platform with the 4 hooves on either rubber 
or concrete. All of the cows were exposed to each standing surface for at least $1 \mathrm{~d}$ before testing. Each cow was tested on each surface and the order of exposure to the treatments was balanced across cows. Cows were tested in groups of 4 animals on 2 different days, with at least $2 \mathrm{~d}$ between treatments. Tests were carried out after morning milking and the time of testing was consistent for each individual.

Weight distribution between legs was measured while cows stood on the weighing platform using the method described by Chapinal et al. (2010a). Data were transmitted to a computer at a rate of 12 reading/s. Readings from the weighing platform in which the total weight recorded was $5 \%$ above or below the mode of the total weight were discarded (Chapinal et al., 2009). The weighing platform was situated at the end of a $13-\mathrm{m}$ long $\times 1.3-\mathrm{m}$ wide ungrooved concrete passageway. A handler walked behind the cows, encouraging them to walk in a consistent manner and enter the weighing platform. Cows were familiarized with the weighing platform and the procedures 4 times/d for at least $4 \mathrm{~d}$ before data collection began. During both training and data collection, when hooves were not on the appropriate recording unit, the cow was gently manipulated to reposition them. Cows were video recorded during the last training session while they walked on the passageway toward the weighing platform, as described in Chapinal et al. (2009). An experienced observer gait scored the cows by using a 1 to 5 numerical rating system (NRS; where $1=$ perfect gait and $5=$ severely lame; Flower and Weary, 2006). Because of screening before the start of the experiment, none of the selected cows was severely lame (mean NRS $\pm \mathrm{SD}=2.4 \pm 0.6$; range $=1.5$ to 3.5 ). In a preliminary analysis, NRS did not have any effect on any of the variables tested and, therefore, it will not be discussed further. Lame animals were not used in this study because of the difficulty in ensuring an appropriate sample size of a given type of painful problem (e.g., sole ulcer).

Concrete or rubber was placed on the top of each recording unit. In order to accommodate the concrete in this location, 2 thin layers of nonslip rubber (0.6 cm-thick each, \#125 2-ply; Cobelt Canada Inc., SaintLaurent, QC, Canada) were first fitted under each $3.7 \mathrm{~cm}$-thick concrete block. The rubber surface was composed of 2 revulcanized rubber mats $(1.9 \mathrm{~cm}$-thick each; Animat, Saint-Élie d'Orford, Quebec, Canada) described in Rushen and de Passillé (2006). A layer of felt (1.5-cm thick, polypropylene/polyester mix) protected with a plastic bag was fitted between the 2 rubber mats to prevent slippage. The position of the hooves was recorded by 4 black and white video cameras (Panasonic CCTV WV-BP310, Matsushita Electric, Mississauga, Ontario, Canada) connected to a digital recording system (Genetec Inc., Saint-Laurent, Quebec, Canada). Two cameras were set up to record a lateral view of the hooves, 1 from each side, whereas the other 2 cameras recorded a front and back view of the hooves. Specialized software was used to record and subsequently watch the videos (Ominicast, Genetec Inc., Saint-Laurent, Quebec, Canada). A single observer watched the videos continuously and counted the number of steps (defined as the number of times the heel was visibly lifted off the standing surface). The number of steps/s was recorded for the analyses. Intra-observer reliability, as measured by percentage agreement, was $91 \%$ for detecting steps in a given second.

Data from $1 \mathrm{~h}$ of standing were summarized for each 10-min period. The dependent variables included the number of steps/10 min and the standard deviation over time of weight applied to the front and rear legs during the same 10-min period. Due to technical problems, some data from the weighing platform were lost for 6 of the cows on 1 of the $2 \mathrm{~d}$ of testing. Thus, only 10 -min periods with more than $75 \%$ of the data available were considered for the analyses, and following this criterion, a total of eleven 10-min periods were discarded from the weighing platform data set. To have a comparable data set for stepping behavior, the same eleven 10-min intervals were also discarded for this dependent variable. Pearson correlation (PROC CORR; SAS Institute, 2003) was used to assess the relationship between the frequency of steps and standard deviation of weight. Each pair of legs (front and rear) and treatment was considered separately. Mixed models (PROC MIXED) were used to test differences in the frequency of steps and the standard deviation of weight applied to the legs in response to treatment and time standing on the weighing platform. Models included cow as a random effect, treatment (concrete or rubber), test group, and order of exposure to each treatment (rubber first or concrete first) as fixed effects, 10-min period as a continuous repeated measure, and the treatment $x$ period interaction. Each pair of legs (front and rear) was considered separately. The autocorrelation structure for each model was chosen according to the lower Bayesian information criterion. Residuals were examined to verify normality and homogeneity of variances. Differences between the front and the rear legs in the standard deviation of weight and the frequency of steps for each surface were compared with 0 (one-sample $t$ test; PROC UNIVARIATE).

A clear correlation was found between the frequency of observed steps and the standard deviation of weight over $1 \mathrm{~h}$ for the front pair of legs on both standing surfaces $(\mathrm{r}=0.73, P=0.007$; and $\mathrm{r}=0.86, P<0.001$ for concrete and rubber, respectively) and for the rear legs when cows were standing on concrete $(\mathrm{r}=0.77, P$ 

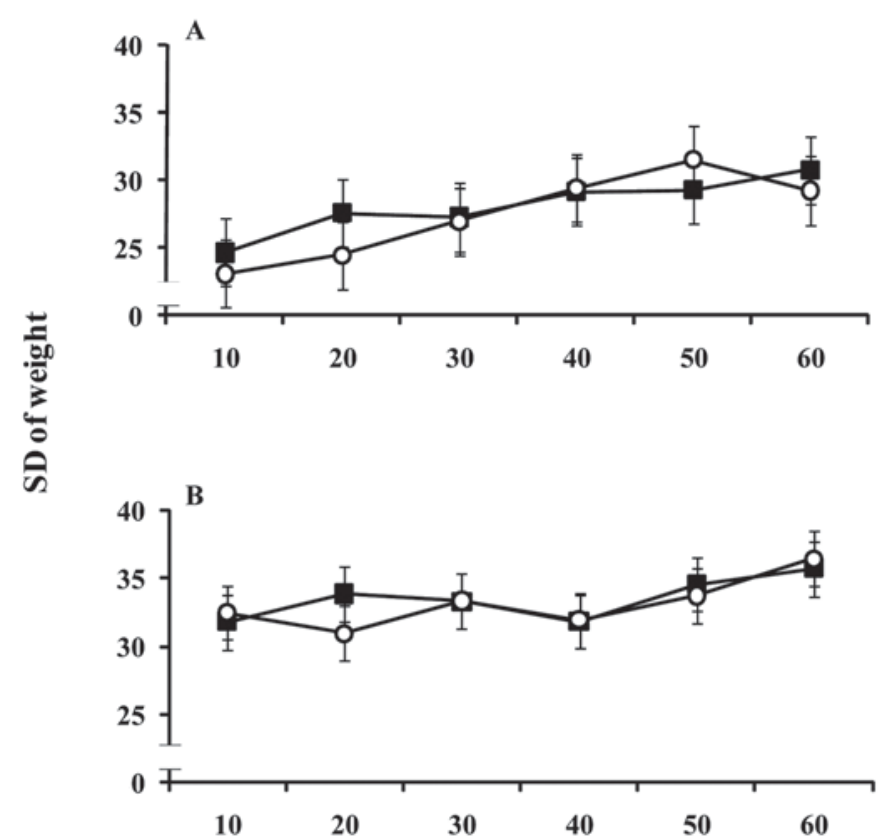

10- $\min$ period within $1 \mathrm{~h}$

Figure 1. Mean $( \pm \mathrm{SE})$ standard deviation $(\mathrm{SD})$ over time of weight applied to the front (A) and rear (B) pair of legs of 12 cows standing on concrete (black square) or rubber (white circle) for $1 \mathrm{~h}$.

$=0.004)$. However, the correlation was not significant for the rear legs when standing on rubber $(\mathrm{r}=0.44, P$ $=0.15$ ), although this result was largely driven by 1 cow that was diagnosed with mastitis on the first day of testing. This cow appeared to have a smaller number of steps than expected, based on the standard deviation of weight in the rear legs on both materials; in other words, she was shifting weight between legs without lifting her hooves off the ground. When this cow was not included, the correlation coefficient increased for the rear legs for both concrete $(\mathrm{r}=0.90, P=0.002)$ and rubber $(\mathrm{r}=0.66, P=0.02)$.

No differences were found in the standard deviation of weight applied to the front or rear legs (Figure 1) or in the frequency of steps (Figure 2) in response to the standing surfaces. No significant interaction existed between the standing surface and time $(P>0.10)$. However, the standard deviation of weight and the frequency of steps increased over time for both treatments and pairs of legs $(P<0.01$ in all cases $)$. The standard deviation of weight and the frequency of steps were greater for the rear than those for the front pair of legs for both standing surfaces $(P<0.05$ in all cases).

Regardless of the standing surface, cows increased the number of steps and the standard deviation of weight applied to contralateral legs over time, and these 2 variables were positively correlated. Therefore, the standing surfaces tested in this experiment did not appear to have any effect on the measures of comfort tested: frequency of steps or weight distribution.

We found an increase in the frequency of steps over time during the $1 \mathrm{~h}$ cows were standing on concrete and rubber, in agreement with the findings of others (Cooper et al., 2007, 2008; Krebs et al., 2011). The standard deviations of weight applied to the front and rear pair of legs were similar to those found in other studies using a comparable weighing platform (Neveux et al., 2006; Pastell and Kujala, 2007; Chapinal et al., 2009). These values were positively correlated to the number of steps taken and also increased over the 1 $\mathrm{h}$ of forced standing. Indeed, to our knowledge, this is the first study to report an increase in the standard deviation of weight applied to contralateral legs over time and to identify that 2 measures of restlessness, steps and shifts in weight distribution, are positively correlated.

No differences existed in measure of comfort, steps, or standard deviation of weight, between flooring materials. One hour of standing may not be long enough to detect differences between standing surfaces in measures of restlessness, although Krebs et al. (2011) observed animals for $4 \mathrm{~h}$ on each surface and were also unable to

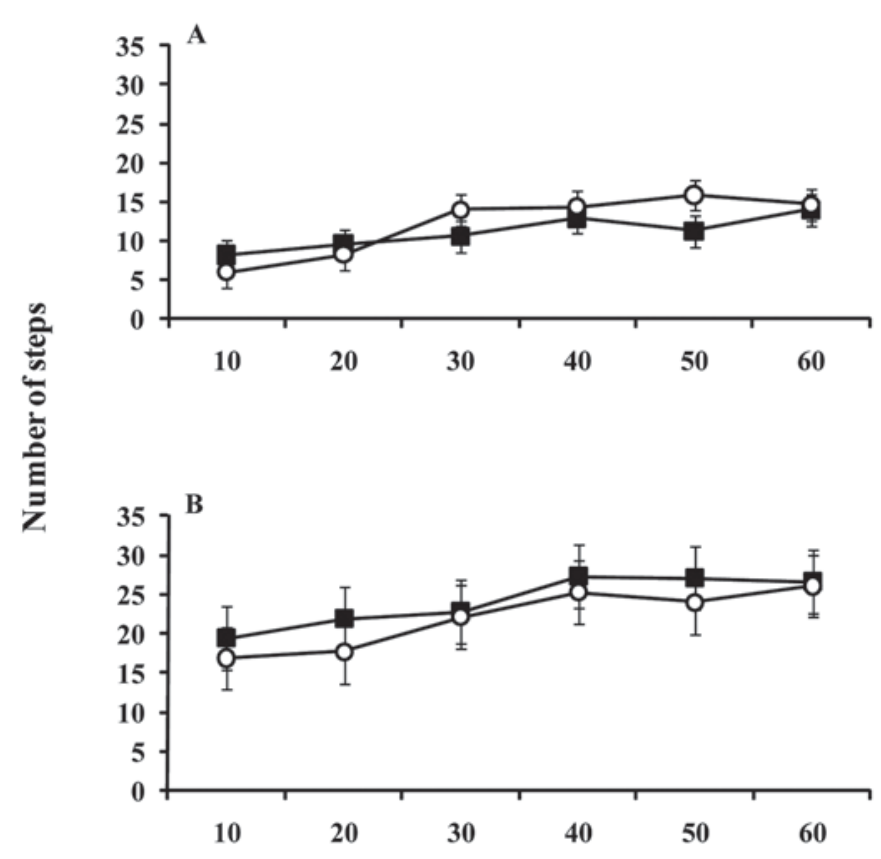

10- $\min$ period within $1 \mathrm{~h}$

Figure 2. Mean $( \pm \mathrm{SE})$ number of steps observed on the front $(\mathrm{A})$ and rear (B) pair of legs of 12 cows standing on concrete (black square) or rubber (white circle) for $1 \mathrm{~h}$. 
detect differences in the number of steps taken for different materials. These results differ from those of other comparisons of rubber and concrete that used other measures. For example, cattle spent more time standing on rubber than on concrete (Fregonesi et al., 2004; Tucker et al., 2006; Boyle et al., 2007) and preferred softer standing surfaces in preference tests (Lowe et al., 2001; Tucker et al., 2006). Cattle were also less likely to slip, took longer strides, and showed less lameness when walking on rubber than on concrete (Telezhenko and Bergsten, 2005; Flower et al., 2007). It is possible that the benefits of rubber are best assessed when active behaviors, such as walking, are included.

Restless behavior may be useful as a measure of flooring comfort in slightly different contexts. Shifting weight between contralateral hooves increases with discomfort caused by lameness (Pastell and Kujala, 2007; Rushen et al., 2007; Chapinal et al., 2010a, b) and surfaces with protruding rocks or screws (Neveux et al., 2006). However, in all of this previous work, the discomfort was likely in or underneath a single leg, compared with that in the current study in which concrete was presented under all 4 legs. Previous work has shown that clinically lame animals show greater responses to improvement in flooring condition (Telezhenko and Bergsten, 2005; Flower et al., 2007). Thus, it would be valuable to compare restless behavior on concrete and rubber standing surfaces using animals that have lameness in a single hoof.

In conclusion, restlessness, as measured by both frequency of steps and weight shifting, increased over $1 \mathrm{~h}$ of forced standing. These 2 measures of restlessness are positively correlated to each other. No differences were observed in these response variables associated with the 2 standing surfaces tested. Measures of restlessness are promising tools for assessing specific types of discomfort (lameness, rocky surfaces), but are not useful for discriminating between rubber and concrete. Additional tools are needed to assess specific characteristics of flooring and we suggest that consideration of both active and stationary behaviors would be a fruitful way forward.

\section{ACKNOWLEDGMENTS}

We thank David Ledgerwood (University of California, Davis), Gosia Zdanowicz (Agriculture and AgriFood Canada), and the faculty, staff, and students at the University of British Columbia's Dairy Education and Research Centre for their help in running the ex- periment and processing the data. The research was funded by the University of California, Davis, Global Animal Partnership, Natural Sciences and Engineering Research Council of Canada and Agriculture and AgriFood Canada.

\section{REFERENCES}

Boyle, L. A., J. F. Mee, and P. J. Kiernan. 2007. The effect of rubber versus concrete passageways in cubicle housing on claw health and reproduction of pluriparous dairy cows. Appl. Anim. Behav. Sci. 106:1-12.

Chapinal, N., A. M. de Passillé, and J. Rushen. 2009. Weight distribution and gait in dairy cattle are affected by milking and late pregnancy. J. Dairy Sci. 92:581-588.

Chapinal, N., A. M. de Passillé, J. Rushen, and S. Wagner. 2010a. Automated methods for the detection of lameness and analgesia in dairy cattle. J. Dairy Sci. 93:2007-2013.

Chapinal, N., A. M. de Passillé, J. Rushen, and S. Wagner. 2010b. Effect of analgesia during hoof trimming on gait, weight distribution and activity of dairy cattle. J. Dairy Sci. 93:3039-3046.

Cooper, M. D., D. R. Arney, and C. J. C. Phillips. 2007. Two- or fourhour lying deprivation on the behavior of lactating dairy cows. J. Dairy Sci. 90:1149-1158.

Cooper, M. D., D. R. Arney, and C. J. C. Phillips. 2008. The effect of temporary deprivation of lying and feeding on the behaviour and production of lactating dairy cows. Animal 2:275-283.

Flower, F. C., A. M. de Passillé, D. M. Weary, D. J. Sanderson, and J. Rushen. 2007. Softer, higher-friction flooring improves gait of cows with and without sole ulcers. J. Dairy Sci. 90:1235-1242.

Flower, F. C., and D. M. Weary. 2006. Effect of hoof pathologies on subjective assessments of dairy cow gait. J. Dairy Sci. 89:139 146.

Fregonesi, J. A., C. B. Tucker, D. M. Weary, F. C. Flower, and T. Vittie. 2004. Effect of rubber flooring in front of the feed bunk on the time budgets of dairy cattle. J. Dairy Sci. 87:1203-1207.

Krebs, N., S. L. Berry, and C. B. Tucker. 2011. Restless behavior increases over time, but not with compressibility of the flooring surface, during forced standing at the feed bunk. J. Dairy Sci. 94:97-105

Lowe, D. E., R. W. J. Steen, and V. E. Beattie. 2001. Preferences of housed finishing beef cattle for different floor types. Anim. Welf. 10:395-404.

Neveux, S., D. M. Weary, J. Rushen, M. A. von Keyserlingk, and A. M. de Passillé. 2006. Hoof discomfort changes how dairy cattle distribute their body weight. J. Dairy Sci. 89:2503-2509.

NRC. 2001. Nutrient Requirements of Dairy Cattle. 7th rev. ed. National Research Council, National Academy Press, Washington, DC.

Pastell, M. E., and M. Kujala. 2007. A probabilistic neural network model for lameness detection. J. Dairy Sci. 90:2283-2292.

Rushen, J., and A. M. de Passillé. 2006. Effects of roughness and compressibility of flooring on cow locomotion. J. Dairy Sci. 89:29652972.

Rushen, J., E. Pombourcq, and A. M. de Passillé. 2007. Validation of two measures of lameness in dairy cows. Appl. Anim. Behav. Sci. 106:173-177.

SAS Institute. 2003. SAS User's Guide. SAS Institute Inc., Cary, NC. Telezhenko, E., and C. Bergsten. 2005. Influence of floor type on the locomotion of dairy cows. Appl. Anim. Behav. Sci. 93:183-197.

Tucker, C. B., D. M. Weary, A. M. de Passillé, B. Campbell, and J. Rushen. 2006. Flooring in front of the feed bunk affects feeding behavior and use of freestalls by dairy cows. J. Dairy Sci. 89:2065-2071. 